\title{
Níveis de lisina digestível de fêmeas suínas selecionadas para deposição de carne magra na carcaça dos 30 aos $60 \mathrm{~kg}^{1}$
}

\author{
Dietary digestible lysine levels of gilts with high genetic potential lean deposition in \\ carcass from 30 to $60 \mathrm{~kg}$
}

\author{
SERAO, Mariana Cruz Rossoni ${ }^{2}$; DONZELE, Juarez Lopes ${ }^{3}$; SILVA, Francisco Carlos \\ de Oliveira $^{4 *}$; OLIVEIRA, Rita Flávia Miranda de ${ }^{3}$; FERREIRA, Aloízio Soares ${ }^{3}$; \\ KILL, João Luís ${ }^{3}$; APOLÔNIO, Lourdes Romão ${ }^{3}$
}

${ }^{1}$ Parte da Tese de Doutorado do primeiro autor.

${ }^{2}$ University of Illinois at Urbana-Champaign, USA.

${ }^{3}$ Universidade Federal de Viçosa, Centro de Ciências Agrárias, Departamento de Zootecnia, Viçosa,Minas Gerais, Brasil.

${ }^{4}$ Empresa de Pesquisa Agropecuária de Minas Gerais, Belo Horizonte, Minas Gerais, Brasil.

*Endereço para correspondência: fcosilva@epamig.br

\section{RESUMO}

Utilizaram-se 50 leitoas de alto potencial genético para deposição de carne magra na carcaça, com peso inicial de $30,17 \pm 2,03$, a fim de avaliar o efeito de níveis crescentes de lisina digestível sobre o desempenho e características de carcaça. Os animais foram distribuídos em delineamento experimental de blocos ao acaso, com cinco tratamentos $(0,83 ; 0,93 ; 1,03 ; 1,13$ e $1,23 \%$ de lisina digestível), cinco repetições e dois animais por unidade experimental. Na distribuição dos animais dentro de cada bloco foi adotado como critério o peso inicial dos animais. Não foi observado efeito dos níveis de lisina digestível sobre o consumo de ração diário e ganho de peso diário. Observou-se efeito quadrático dos tratamentos sobre a conversão alimentar, que melhorou até o nível estimado de $1,11 \%$ de lisina digestível. Foi observado efeito linear dos níveis de lisina sobre a taxa de deposição de proteína diária, entretanto, o modelo Linear Response Plateau foi o que melhor se ajustou aos dados e estimou o nível de $1,09 \%$ de lisina digestível para melhor deposição de proteína diária. Não foi observado efeito dos tratamentos sobre a taxa de deposição diária de gordura. Conclui-se que o nível de $1,11 \%$ de lisina digestível proporciona os melhores resultados de desempenho e de taxa de deposição de proteína diária na carcaça de fềmeas suínas de alto potencial genético para deposição de carne magra na carcaça, dos 30 aos $60 \mathrm{~kg}$.

\section{SUMMARY}

Fifty gilts were used, with initial weight of $30.17 \pm 2.03 \mathrm{~kg}$, to evaluate the effect of increasing levels of digestible lysine on performance and carcass characteristics. The animals were distributed in a random block experimental design, with five treatments $(0.83$; $0.93 ; 1.03 ; 1.13$ and $1,23 \%$ of digestible lysine), five replicates and two animals which were considered one experimental unit. The criteria for the formation of the blocks were the animals initial weight. There was no effect of levels of digestible lysine on daily feed intake and daily weight gain. A quadratic effect was observed on feed conversion that improved until an estimated level of $1.11 \%$ of digestible lysine. A linear effect was observed on daily protein deposition, however, the data were adjusted through the Linear Response Plateau model, which indicated the estimated level of $1.09 \%$ of digestible lysine for best daily protein deposition. No effect was observed on daily fat deposition among the treatments. It conclude that the level of $1.11 \%$ of digestible lysine provided the best performance and daily protein deposition results for gilts with high potential for lean deposition, from 30 to $60 \mathrm{~kg}$.

Key words: digestible amino acid, performance, requirement, growing-phase

Palavras-chaves: aminoácido digestível, desempenho, exigência, fase de crescimento 


\section{INTRODUÇÃO}

A obtenção de novas progênies de suínos tem sido feita pela seleção genética de animais com alto potencial genético para deposição de carne magra na carcaça. Entretanto, suínos provenientes de diferentes grupos genéticos não possuem a mesma capacidade de conversão de alimento em proteína e podem exigir quantidades distintas de nutrientes para alcançar seu máximo potencial genético. Assim, suínos com alta taxa de ganho proteico exigem maior consumo de aminoácidos, principalmente lisina, para exteriorizar todo $\mathrm{o}$ seu potencial (BATISTA et al., 2011).

A lisina tem sido considerada o primeiro aminoácido limitante em rações para suínos à base de milho e farelo de soja, e diretamente responsável pelo aumento na deposição de músculo na carcaça (SILVA et al., 2009). Assim, as melhores respostas de desempenho e de carcaça podem ser associadas ao nível de lisina da ração.

Por outro lado, tem-se observado que as exigências de suínos em crescimento, principalmente de lisina, tem sido alterada (WARNANTS et al., 2003; KEIFER et al., 2011). Esta variação pode ocorrer em razão do estádio fisiológico do animal, do consumo ou as diferenças na composição da ração (KILL et al., 2003) e ainda podem ser modificadas em razão do genótipo, sexo, idade, temperatura, saúde, densidade populacional, entre outros fatores (NRC, 1998).

Diferenças na capacidade de síntese de tecido magro foram observadas em linhagens com diferente potencial para deposição de carne na carcaça (PUPA et al., 2001). Assim, suínos com genótipos superiores exigem uma maior quantidade de proteína e aminoácidos na ração para suportar alta taxa de deposição de proteína, consequentemente, quanto maior a capacidade dos suínos de depositar carne magra na carcaça, maior será a exigência diária de lisina para maximizar seu desempenho e a taxa de deposição proteica (ROSSONI et al., 2009).

A taxa de crescimento e o consumo maior têm sido observados em machos castrados quando comparados com fêmeas suínas. No entanto, estas possuem melhor eficiência na conversão de alimento em peso. $O$ aumento na deposição de tecido magro associado ao menor consumo diário de ração pode resultar, nas fêmeas suínas, em maior exigência de aminoácidos essenciais em relação aos machos castrados. Assim, objetivou-se com este trabalho avaliar o efeito de níveis crescentes de lisina digestível sobre o desempenho e características de carcaça de fêmeas suínas com alto potencial genético para deposição de tecido magro na carcaça dos 30 aos $60 \mathrm{~kg}$.

\section{MATERIAL E MÉTODOS}

O experimento foi conduzido no galpão experimental da granja de suínos da Empresa de Pesquisa Agropecuária de Minas Gerais (EPAMIG), localizado na Fazenda Experimental Vale do Piranga, município de Oratórios, MG.

Foram utilizadas 50 leitoas, híbridas comerciais, de alto potencial genético para deposição de carne magra na carcaça, com peso inicial de 30,17 \pm 2,03, distribuídas em delineamento experimental de blocos ao acaso, com cinco tratamentos (níveis de lisina digestível), cinco repetições e dois animais por unidade experimental. $\mathrm{Na}$ distribuição dos animais dentro de cada bloco foi adotado como critério o peso dos animais. 
Os animais foram alojados em baias equipadas com comedouros semi automáticos e bebedouros tipo chupeta, com piso de concreto e cobertura de telha de cimento amianto. Foi utilizado um termômetro de máxima e mínima, colocado no interior do galpão, para registro diário da temperatura.

As rações experimentais foram formuladas à base de milho e farelo de soja, suplementadas com minerais e vitaminas, para atender as exigências nutricionais dos animais de acordo com Rostagno et al. (2000), exceto para proteína bruta e aminoácidos. Os tratamentos corresponderam a uma ração basal com $18,59 \%$ de $\mathrm{PB}$ e $3.218 \mathrm{kcal}$ de $\mathrm{EM} / \mathrm{kg}$, suplementadas com L-lisina $\mathrm{HCl}$, o que resultou em rações com 0,$83 ; 0,93 ; 1,03 ; 1,13 \mathrm{e}$ $1,23 \%$ de lisina digestível. As rações foram suplementadas com níveis crescentes de aminoácidos industriais resultando em rações com relações aminoacídicas entre lisina e os demais aminoácidos essenciais estabelecidas, com base na digestibilidade verdadeira, sendo as relações aminoacídicas das rações atendidas de acordo com aquelas preconizadas por Rostagno et al. (2000) para proteína ideal. As composições centesimais e determinadas das dietas são apresentadas na Tabela 1. O fornecimento das dietas experimentais e de água aos animais durante todo período experimental foi à vontade.

Para determinação do ganho de peso, consumo de ração, conversão alimentar e do consumo de lisina foram feitas pesagens semanais das rações e respectivas sobras e dos animais, no início e no final do experimento.

Ao final do experimento, quando atingiram o peso de $60,94 \pm 1,76 \mathrm{~kg}$, um animal de cada unidade experimental com peso mais próximo da média de peso dos animais do bloco, foi utilizado para avaliar a composição química e as deposições de proteína e gordura na carcaça. Após jejum de 24 horas, os animais foram abatidos por sangramento, depilados com lança-chamas e faca, eviscerados, e as carcaças inteiras, incluindo cabeça e pés, foram pesadas.

Posteriormente, a meia carcaça direita foi triturada por 20 minutos, em cutter comercial de 30 HP e $1.775 \mathrm{rpm}$. Após homogeneização, amostras foram obtidas para posteriores análises, conforme metodologia descrita por Moreira et al. (2005) e armazenadas a $12^{\circ} \mathrm{C}$. Um grupo adicional de cinco animais do mesmo lote e peso inicial foi abatido no início do experimento para determinação da composição inicial das carcaças dos suínos.

As análises dos ingredientes, das rações e das carcaças foram realizadas no Laboratório de Nutrição Animal do Departamento de Zootecnia da Universidade Federal de Viçosa, de acordo com as técnicas descritas por Silva (2002).

Os parâmetros avaliados foram: ganho de peso médio diário, consumo de ração médio diário, conversão alimentar, consumo de lisina médio diário, taxa de deposição de proteína e de deposição de gordura nas carcaças.

Os dados observados foram submetidos à análise de variância, com a utilização do Sistema de Análise Estatística e Genética - SAEG (UFV, 2005). As estimativas de exigência de lisina digestível foram obtidas por meio de análises de regressão linear, quadrática e ou descontínuo "Linear Response Plateau" (LRP), conforme o melhor ajustamento obtido para cada variável. 
Rev. Bras. Saúde Prod. Anim., Salvador, v.13, n.2, p.433-443 abr./jun., 2012 http://www.rbspa.ufba.br ISSN 15199940

Tabela 1. Composição centesimal e determinada das dietas experimentais

\begin{tabular}{|c|c|c|c|c|c|}
\hline \multirow{2}{*}{ Ingredientes $(\%)$} & \multicolumn{5}{|c|}{ Níveis de Lisina Digestível (\%) } \\
\hline & 0,83 & 0,93 & 1,03 & 1,13 & 1,23 \\
\hline Milho & 65,509 & 65,509 & 65,509 & 65,509 & 65,509 \\
\hline Farelo de soja & 29,255 & 29,255 & 29,255 & 29,255 & 29,255 \\
\hline Amido & 1,721 & 1,461 & 1,153 & 0,784 & 0,345 \\
\hline Fosfato bicálcico & 1,362 & 1,362 & 1,362 & 1,362 & 1,362 \\
\hline Calcário & 0,805 & 0,805 & 0,805 & 0,805 & 0,805 \\
\hline Óleo de Soja & 0,690 & 0,690 & 0,690 & 0,690 & 0,690 \\
\hline DL-metionina (99\%) & 0,010 & 0,079 & 0,155 & 0,213 & 0,284 \\
\hline L-Lisina $\mathrm{HCl}(99 \%)$ & - & 0,129 & 0,258 & 0,388 & 0,517 \\
\hline L-Treonina $(98,5 \%)$ & - & 0,062 & 0,142 & 0,218 & 0,302 \\
\hline L-Triptofano (99\%) & - & - & 0,023 & 0,048 & 0,074 \\
\hline L-Valina $(98,5 \%)$ & - & - & - & 0,057 & 0,123 \\
\hline L-Isoleucina (99\%) & - & - & - & 0,023 & 0,086 \\
\hline Premix mineral $^{1}$ & 0,100 & 0,100 & 0,100 & 0,100 & 0,100 \\
\hline Premix vitamínico $^{2}$ & 0,200 & 0,200 & 0,200 & 0,200 & 0,200 \\
\hline Promotor de crescimento & 0,010 & 0,010 & 0,010 & 0,010 & 0,010 \\
\hline BHT & 0,010 & 0,010 & 0,010 & 0,010 & 0,010 \\
\hline Sal comum & 0,328 & 0,328 & 0,328 & 0,328 & 0,328 \\
\hline Total & 100,000 & 100,000 & 100,000 & 100,000 & 100,000 \\
\hline \multicolumn{6}{|l|}{ Composição determinada $^{3}$} \\
\hline Energia digestível (kcal/kg) & 3.400 & 3.395 & 3.388 & 3.379 & 3.368 \\
\hline Energia metabolizável $(\mathrm{kcal} / \mathrm{kg})$ & 3.218 & 3.218 & 3.218 & 3.218 & 3.218 \\
\hline Proteína bruta (\%) & 18,592 & 18,798 & 19,045 & 19,323 & 19,629 \\
\hline Lisina total $(\%)$ & 0,946 & 1,048 & 1,149 & 1,250 & 1,351 \\
\hline Lisina digestível (\%) & 0,830 & 0,930 & 1,030 & 1,130 & 1,230 \\
\hline Met. + cis. digestível (\%) & 0,539 & 0,608 & 0,763 & 0,976 & 1,260 \\
\hline Isoleucina digestível (\%) & 0,660 & 0,660 & 0,660 & 0,683 & 0,769 \\
\hline Treonina digestível (\%) & 0,670 & 0,732 & 0,874 & 1,092 & 1,394 \\
\hline Triptofano digestível (\%) & 0,190 & 0,190 & 0,213 & 0,261 & 0,335 \\
\hline Valina digestível (\%) & 0,726 & 0,726 & 0,726 & 0,783 & 0,906 \\
\hline Cálcio (\%) & 0,760 & 0,760 & 0,760 & 0,760 & 0,760 \\
\hline Fósforo disponível (\%) & 0,360 & 0,360 & 0,360 & 0,360 & 0,360 \\
\hline Sódio (\%) & 0,170 & 0,170 & 0,170 & 0,170 & 0,170 \\
\hline
\end{tabular}

${ }^{1}$ Conteúdo/kg de produto: Ca: 98,80g; Co: 185,0mg; Cu: 15.750mg; Fe: 26.250mg; I: 1.470mg; Mn: 41.850mg; e Zn: $77.999 \mathrm{mg}$.

${ }^{2}$ Conteúdo/kg de produto: ácido fólico: $351,75 \mathrm{mg}$; ácido pantotênico: $3.500 \mathrm{mg}$; antioxidante (BHT): $1.500 \mathrm{mg}$; biotina: $18,90 \mathrm{mg}$; colina: $52,50 \mathrm{~g}$; niacina: $6.930 \mathrm{mg}$; vit. B6: $630 \mathrm{mg}$; vit. B2: $1.400 \mathrm{mg}$; Se: $131,25 \mathrm{mg}$; vit. B1: 350mg; vit. A: 1.750 UI; vit. B12 8.750,70mcg; vit. D3: 700.000 UI; vit. E: $3.500 \mathrm{mg}$; e vit. K3: 700mg.

${ }^{3}$ Valores calculados com base na análise de aminoácidos da ração basal aplicando o coeficiente de digestibilidade segundo Rostagno et al. (2000).

\section{RESULTADOS E DISCUSSÃO}

As temperaturas médias, mínima e máxima, verificadas no período foram, respectivamente, $25,4 \pm 1,33^{\circ} \mathrm{C}$ e $29,1 \pm$ $1,76^{\circ} \mathrm{C}$. Ao se considerar que a faixa ideal de temperatura para suínos na fase de crescimento sugerida por Coffey et al. (2000) está entre 16 e $24^{\circ} \mathrm{C}$ para melhor desempenho produtivo e qualidade de carcaça, constatou-se, com base na 
variação da temperatura ocorrida na condução do experimento, que os animais foram submetidos a períodos de estresse térmico.

Nos resultados de consumo de ração diário (CDR), ganho de peso diário (GPD) e da conversão alimentar (CA) de leitoas de alto potencial genético para deposição de carne na carcaça, consumindo rações com diferentes níveis de lisina digestível, dos 30 a $60 \mathrm{~kg}$, apresentados na Tabela 2, não foi observado efeito $(\mathrm{P}>0,05)$ dos níveis de lisina sobre o consumo de ração. Do mesmo modo, Souza (1997), Fontes et al. (2000) e Kill (2002), também não encontraram efeito dos níveis de lisina sobre o CRD de leitoas dos 30 aos $60 \mathrm{~kg}$. Mais recentemente, Abreu et al. (2007), ao trabalharem com leitões machos castrados, dos 30 aos $60 \mathrm{~kg}$, também não encontraram variação significativa no consumo voluntário de alimento quando os níveis de lisina digestível variaram de 0,80 a $1,10 \%$.

Tabela 2. Desempenho carcaça de fêmeas suínas recebendo diferentes níveis de lisina digestível dos 30 aos $60 \mathrm{~kg}$

\begin{tabular}{lrrrrrr}
\hline \multirow{2}{*}{ Variáveis } & \multicolumn{5}{c}{ Níveis de Lisina Digestível $(\%)$} & \multirow{2}{*}{ CV $(\%)$} \\
\cline { 2 - 6 } & 0,83 & 0,93 & 1,03 & 1,13 & 1,23 & \\
\hline Consumo de ração diário $(\mathrm{g})$ & 2.219 & 2.059 & 2.159 & 2.107 & 2.141 & 5,1 \\
Ganho de peso diário $(\mathrm{g})$ & 1.046 & 1.063 & 1.135 & 1.021 & 1.076 & 5,7 \\
Consumo de lisina diário $(\mathrm{g}){ }^{1}$ & 18,86 & 19,56 & 22,62 & 24,23 & 26,76 & 8,3 \\
Conversão alimentar $^{2 /}$ & 2,12 & 1,96 & 1,90 & 2,06 & 1,99 & 3,6 \\
\hline
\end{tabular}

${ }^{1}$ Efeito linear $(\mathrm{P}<0,001)$.

${ }^{2}$ Efeito quadrático $(\mathrm{P}<0,02)$.

Por outro lado, Fontes et al. (2005) e Fernández-Figares et al. (2007), constataram redução no CRD de leitoas na fase de crescimento à medida que se elevou a concentração de lisina digestível na ração.

Os resultados de CRD obtidos confirmam a proposição de Edmonds e Baker (1987), de que os suínos são capazes de tolerar consideráveis excessos de aminoácidos sem alteração na ingestão voluntária de alimento.

Outro fator que pode ter contribuído para que não ocorresse variação no CRD foi a utilização do conceito da proteína ideal na formulação das rações nos diferentes tratamentos. De acordo Kill (2002), suínos alimentados com rações formuladas, nas quais foram mantidas as relações entre aminoácidos essenciais com a lisina, são menos susceptíveis a variações no consumo alimentar.

O ganho de peso diário (GPD) não foi influenciado $(\mathrm{P}>0,05)$ pelos níveis de lisina digestível das rações. De forma semelhante, Fontes et al. (2000), Kill (2002), Fontes et al. (2005) e Abreu et al. (2007), também não observaram variação significativa dos níveis de lisina sobre o GPD dos animais. Em contrapartida, Oliveira et al. (2009) observaram aumento linear sobre a taxa de crescimento de suínos machos castrados dos 30 aos $60 \mathrm{~kg}$ quando avaliaram níveis entre 0,7 e $1,10 \%$ de lisina digestível, enquanto James et al. (2002) e Colina et al. (2003) observaram influência positiva dos níveis de lisina sobre a eficiência de utilização do 
alimento para ganho de peso em suínos na fase inicial.

As diferenças de respostas dos suínos aos níveis de lisina observadas entre os trabalhos, provavelmente reflete diferenças na capacidade genética para deposição de proteína, bem como da fase de crescimento dos animais utilizados nos diferentes estudos.

Embora não tenha ocorrido efeito significativo dos tratamentos sobre o ganho de peso dos animais, constatouse uma melhora de $8,5 \%$ no valor absoluto do GPD quando o nível de lisina digestível da ração aumentou de $0,83(1.046 \mathrm{~g})$ para $1,03 \%(1.135 \mathrm{~g})$.

$\mathrm{O}$ consumo diário de lisina (CDL) aumentou $(\mathrm{P}<0,001)$ de forma linear à medida que se elevou o nível de lisina digestível da ração segundo a equação $\mathrm{Y}=0,8863+20,4811 \mathrm{X}\left(\mathrm{r}^{2}=0,72\right) . \mathrm{O}$ fato do CRD não ter variado entre os tratamentos justifica a relação linear positiva observada entre o consumo de lisina e o seu nível na ração. Relação positiva entre o consumo de lisina com a sua concentração na dieta também foi observado por Fontes et al. (2000), Fontes et al. (2005) e Abreu et al. (2007).

Os níveis de lisina ração na influenciaram $(\mathrm{P}<0,02)$ a conversão alimentar (CA), que melhorou de forma quadrática até o nível estimado de $1,11 \%$ (Figura 1), correspondente a um consumo de lisina diário de 23,62g.

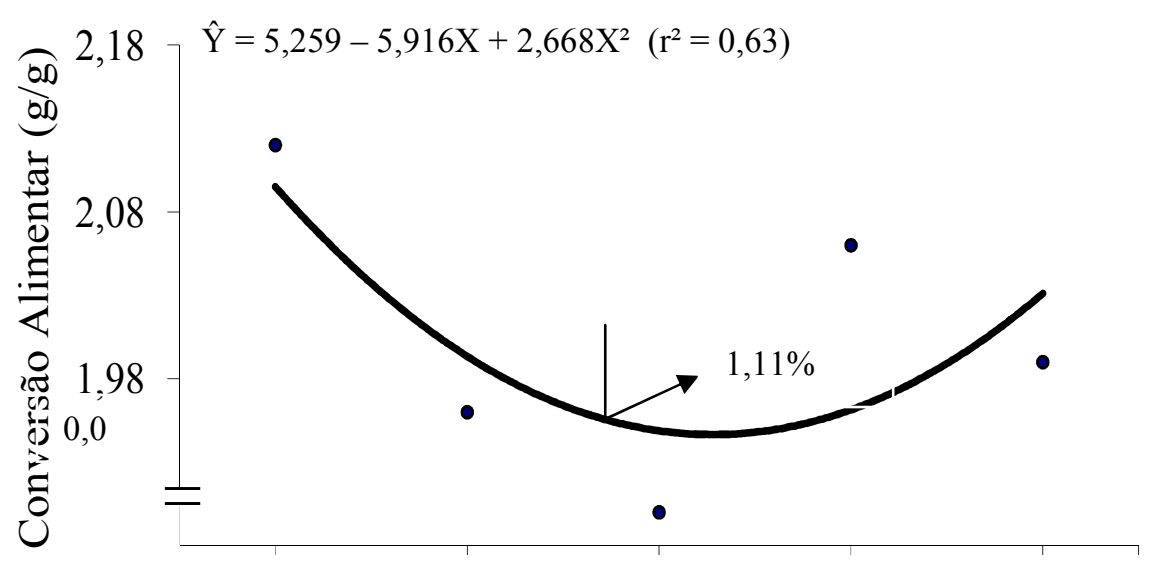

Figura 1. Efeito do nível de lisina digestível sobre a conversão alimentar de leitoas de 30 a $60 \mathrm{~kg}$

Os resultados estão de acordo com as recomendações de Fontes et al. (2000) e Rostagno et al. (2005), tanto para CA como para CDL. No entanto, resultados inferiores foram observados por Kill (2002), que obtiveram melhores respostas de CA no nível de $0,98 \%$ de lisina digestível para leitoas na fase de crescimento. Do mesmo modo, a recomendação para suínos na fase de crescimento recomendado pelo NRC (1998) de 0,83\% de lisina digestível, também está abaixo do resultado do presente trabalho.

A variação na conversão alimentar, entre os diferentes trabalhos, pode ser atribuída ao nível de lisina utilizada nas dietas experimentais, ao sexo, à fase de crescimento e ao potencial genético dos animais. Segundo Santos et al. (2011), animais de alto potencial genético são eficientes na utilização do alimento para deposição de carne magra e respondem 
de forma quadrática ao aumento no nível de lisina das dietas.

Com os resultados de CA e GPD, podese deduzir que a exigência de lisina digestível para máxima eficiência de utilização de alimento para ganho é maior que a exigência para melhores resultados de GPD. Este padrão de resposta foi similar àquelas observadas por Fontes et al. (2000) e Abreu et al. (2007). A melhora verificada na CA entre os níveis de 0,83 a $1,03 \%$ de lisina digestível seria um indicativo de que, provavelmente, a composição do ganho tenha sido alterada, aumentado proporcionalmente a deposição de proteína em relação à de gordura. Embora, de acordo com Chen et al. (1999) a deposição de proteína possa resultar em menor eficiência energética de ganho, Hahn et al. (1995) sugeriram que a alteração na composição do ganho, ao favorecer a deposição de proteína resulta na melhora da eficiência de utilização do alimento por unidade de ganho de peso, pelo fato de que, na deposição de tecido proteico, ocorre, simultaneamente, maior deposição de água, contrariamente à deposição de tecido adiposo.

Os resultados de taxa de deposição de proteína (TDP) e de gordura (TDG) na carcaça de leitoas de alto potencial genético para deposição de carne na carcaça, dos 30 a $60 \mathrm{~kg}$, encontram-se na Tabela 3, onde é observado efeito $(\mathrm{P}<0,05)$ dos níveis de lisina sobre a taxa de deposição de proteína diária, que aumentou de forma linear (Figura 2). No entanto, o modelo Linear Response Plateau (LRP) foi o que melhor se ajustou aos dados, estimando em 1,09\% o nível de lisina a partir do qual os dados permaneceram em um platô. Neste nível de lisina os animais apresentaram um consumo estimado de $23,22 \mathrm{~g} /$ dia de lisina digestível.

A exigência de lisina digestível de $23,22 \mathrm{~g}$ para maximizar a deposição de proteína na carcaça dos animais neste estudo, ficou acima daquele de 17,91g obtidos por Fontes et al. (2005), ao trabalharem com fêmeas de alto potencial genético, dos 30 aos $60 \mathrm{~kg}$.

Uma das hipóteses para esta resposta é de que ao nível de 1,09\% de lisina digestível, a exigência dos animais para este aminoácido alcançou o potencial máximo de deposição de proteínas. Conforme Abreu et al. (2007), quando a energia da ração não é fator limitante, os suínos respondem a aumentos dos níveis de lisina da ração até o ponto de máxima deposição de proteína na carcaça, determinado pela genética. Assim, a deposição de tecido muscular com o consumo de energia só é eficientemente obtida se o aporte de aminoácidos, principalmente lisina, for suficiente para permitir a expressão genética do animal (MAIN et al., 2008). Dessa forma, suínos com altas taxas de deposição de proteína têm exigências mais altas de aminoácidos para expressar seu potencial genético de crescimento e eficiência para deposição de tecido muscular.

Tabela 3. Desempenho e características de carcaça de fêmeas suínas recebendo diferentes níveis de lisina digestível dos 30 aos $60 \mathrm{~kg}$

\begin{tabular}{lcccccc}
\hline \multirow{2}{*}{ Taxa de Deposição } & \multicolumn{5}{c}{ Níveis de Lisina Digestível (\%) } & \multirow{2}{*}{ CV $(\%)$} \\
\cline { 2 - 6 } & 0,83 & 0,93 & 1,03 & 1,13 & 1,23 & \\
\hline Proteína (g/dia) & 129,60 & 135,70 & 156,18 & 165,39 & 161,14 & 13,7 \\
Gordura (g/dia) & 165,74 & 138,43 & 162,05 & 155,04 & 154,24 & 16,9 \\
\hline
\end{tabular}

${ }^{1 / E}$ Efeito linear $(\mathrm{P}<0,05)$. 


$$
\begin{aligned}
& \hat{Y}=53,164+91,93 X\left(r^{2}=0,81\right) \ldots \ldots \ldots \\
& \hat{Y}=21,42+127,85 X\left(r^{2}=0,96\right)
\end{aligned}
$$

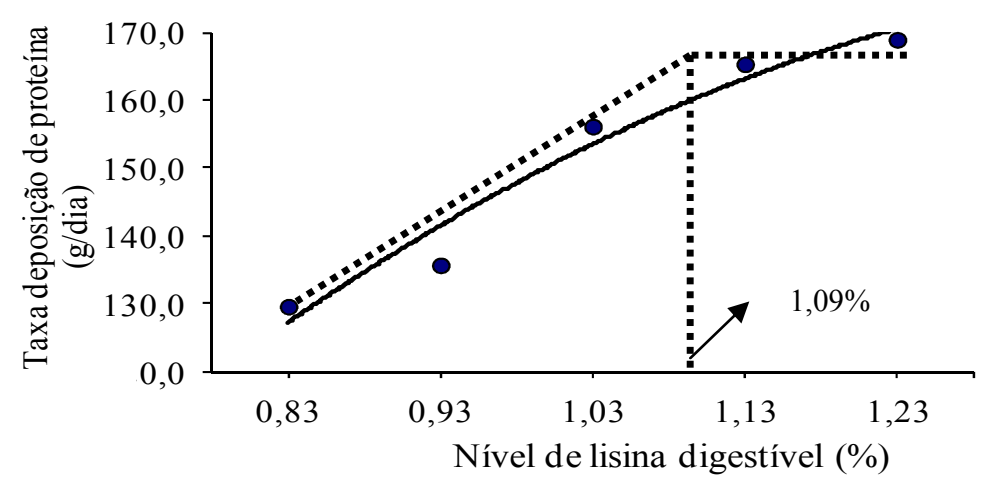

Figura 2. Efeito do nível de lisina digestível sobre a taxa de deposição de proteína de leitoas de 30 a $60 \mathrm{~kg}$

A resposta da TDP se assemelha com o nível de $1,11 \%$ de lisina digestível estimado para melhor CA. Estes resultados, aliados ao fato de não ter ocorrido efeito significativo sobre $\mathrm{o}$ GPD, podem ser indicativos de um aumento no nível de IGF-1 circulante, que é um hormônio ligado à deposição de proteína muscular, nos tratamentos com níveis mais elevados de lisina, o que resulta em maior deposição de proteína diária. Ren et al. (2007), ao avaliarem níveis de lisina na ração de suínos machos castrados, observaram interação significativa do aumento IGF1 no plasma com o aumento da retenção de nitrogênio diária, quando os animais receberam níveis elevados de lisina na ração.

Ao estudarem fêmeas suínas que recebiam dietas com $72 \%$ de redução do nível de lisina, Ferández-Figares et al. (2007) observaram redução significativa da concentração de IGF-1 plasmática associada a menores taxas de retenção de nitrogênio dos animais que receberam a ração com deficiência de lisina quando comparados com os do grupo controle. Do mesmo modo, Katsumata et al. (2002) também observaram redução na concentração de IGF-1 no plasma de suínos alimentados com dietas que continham $61 \%$ de deficiência de lisina na ração.

A deposição de gordura na carcaça dos animais não foi influenciada $(\mathrm{P}>0,05)$ pelos níveis de lisina da ração. Este resultado foi semelhante ao obtido por Fontes et al. (2000) e Abreu et al. (2007) e difere dos de Fontes et al. (2005), que encontraram um efeito quadrático $(\mathrm{P}<0,02)$ do nível de lisina na ração sobre a deposição de gordura, que diminuiu até o nível estimado de $1,09 \%$ de lisina total.

Assim, pode-se concluir que o nível de $1,11 \%$ de lisina digestível, correspondente a um consumo de 23,62g/dia de lisina digestível, proporciona os melhores resultados de desempenho e de taxa de deposição de proteína diária em fêmeas suínas de alto potencial genético para deposição de carne magra na carcaça, dos 30 aos $60 \mathrm{~kg}$.

\section{AGRADECIMENTO}

À AGROCERES NUTRIÇÃO ANIMAL, pela cessão dos animais e das rações experimentais. 
Rev. Bras. Saúde Prod. Anim., Salvador, v.13, n.2, p.433-443 abr./jun., 2012 http://www.rbspa.ufba.br ISSN 15199940

\section{REFERÊNCIAS}

ABREU, M.L.T.; DONZELE, J.L.; OLIVEIRA, R.F.M. OLIVEIRA, A.L.S.; HAESE, E.; PEREIRA, A.A. Níveis de lisina digestível em rações, utilizando-se o conceito de proteína ideal, para suínos machos castrados de alto potencial genético, dos 30 aos $60 \mathrm{~kg}$. Revista Brasileira de

Zootecnia, v.36, n.1, p.62-67, 2007.

BATISTA, R.M.; OLIVEIRA, R.F.M., DONZELE, J.L.; OLIVEIRA, W.P.; LIMA, A.L.; ABREU, M.L.T. Lisina digestível para suínos machos castrados de alta deposição de carne submetidos a estresse por calor dos 30 aos $60 \mathrm{~kg}$. Revista Brasileira de Zootecnia, v.40, n.9, p.1925-1932, 2011.

CHEN, H.Y.; LEWIS, A.J.; MILLER, P.S.; YEN, J.T. The effect of excess protein on growth performance and protein metabolism of finishing barrows and gilts. Journal of Animal Science, v.77, p.3238-3247, 1999.

COFFEY, R.D.; PARKER, G.R.; LAURENT, K.M. Feeding growingfinishing pigs to maximize lean grow rate. University of Kentucky. College of Agriculture, 2000.

Disponível em:

$<$ http://www.animalgenome.org/edu/ $\mathrm{PIH} /$ prod grow finish.pdf $>$. Acesso em: 14 maio 2010.

COLINA, J.J.; MILLER, P.S.; LEWIS, A.J.; FISCHER, R.L. Influence of crystalline or proteinbound lysine on lysine utilization for growth in pigs. Nebraska Swine Report, p.42-47, 2003.
EDMONDS M.S.; BAKER, D.H.

Amino acid excesses for young pigs:

effects of excess methionine, tryptophan, threonine or leucine.

Journal of Animal Science, v.64, n.6, p.1664-1671, 1987.

FERNÁMDEZ-FÍGARES, I.; LACHICA, M.; NIETO, R.; RIVERAFERRE, M. G. Ferum profile of metabolites and hormones in obese (Iberian) and lean (Landrace) growing gilts fed balanced or lisine deficient diets. Livestock Science, v.110, p.7381, 2007.

FONTES, D.O.; DONZELE, J.L.; FERREIRA, A.S.; OLIVEIRA, R.F.M.; GOMES JÚNIOR, C.A.G. Níveis de lisina para leitoas selecionadas geneticamente para deposição de carne magra na carcaça, dos 60 aos $95 \mathrm{~kg}$.

Revista Brasileira de Zootecnia, v.28, n.3, p.784-793, 2000.

FONTES, D.O.; DONZELE, J.L.; OLIVEIRA, R.F.M.; LOPES, D.C.; FERREIRA, A.S.; SILVA, F.C.O.

Níveis de lisina para leitoas selecionadas geneticamente para deposição de carne magra na carcaça, dos 30 aos 60kg. Revista Brasileira de Zootecnia, v.34, n.1, p.81-89, 2005.

HAHN, J.D.; BIEHL, R.R.; BAKER, D.H. Ideal digestible lysine level for early and late-finishing swine. Journal of Animal Science, v.73, n.3, p.773784, 1995.

JAMES, B.W.; TOKACH, M.D.; GOODBAND, R.D. NELSSEN, J.L.; DRITZ, S.S.; HASTAD, C.W.; LAWRENCE, K.R.; USRY, J.L. The optimal true ileal digestible lysine requirement for nursery pigs between 27 to 44 lb. Swine Day, p.63-65, 2002. 
Rev. Bras. Saúde Prod. Anim., Salvador, v.13, n.2, p.433-443 abr./jun., 2012 http://www.rbspa.ufba.br ISSN 15199940

KATSUMATA, M.; KAWAKAMI, S.; KAJI, Y.; TAKADA, R.; DAUCEY, M.J. Differential regulation of porcine hepatic IGF-I mRNA expression and plasma IGF-I concentration by a low lysine diet. Journal of Nutrition, n.132, p.688-692, 2002.

KIEFER, C.; DONZELE, J.L.; OLIVEIRA, R.F.M. Planos nutricionais de lisina digestível para suínos machos imunocastrados em crescimento e terminação. Revista Brasileira de Zootecnia, v.40, n.9, p.1955-1960, 2011.

KILL, J.L. Níveis de lisina e planos de nutrição, para as fases de crescimento e terminação, para leitoas de alto potencial genético para deposição de carne magra. 2002. 73p. Tese (Doutorado em Zootecnia) - Universidade Federal de Viçosa, Viçosa.

KILL, J.L.; DONZELE, J.L.; OLIVEIRA, R.F.M.; FERREIRA, A.S.; LOPES, D.C.; SILVA, F.C.O.; SILVA, M.V.G.B. Níveis de lisina para leitoas com alto potencial genético para deposição de carne magra dos 65 aos 95kg. Revista Brasileira de Zootecnia, v.32, n.6, p.1647-1656, 2003. Suppl. 1.

MAIN, R.G.; DRITZ, S.S.; TOKACH, M.D.; GOODBAND, R.D.; NELSSEN, J.L. Determining an optimum lysine:calorie ratio for barrows and gilts in a commercial finishing facility. Journal of Animal Science, v.86, p.2190-2207, 2008.

MOREIRA, H.F.V.; FONTES, D.O.; SILVA, F.C.O.; SILVA, M.A.; FONTES, F.A.P.V.; GOMES, F.E.; ROSSONI, M.C. Níveis de Lisina para Leitoas dos 6 aos $16 \mathrm{~kg}$ com Alto Potencial para Deposição de Carne Magra na Carcaça. Revista Brasileira de Zootecnia, v.34, n.46, p.1210-1216, 2005.
NACIONAL RESEARCH COUNCIL - NRC. Nutrient requirements of swine. 10.ed. Washington-DC: National Academy of Science, 1998. 189p. (Nutrient Requirements of Domestic Animals, 2).

OLIVEIRA, A.L.S.; DONZELE, J.L.; ABREU, M.L.T.; SILVA, F.C.O.; OLIVIERA, R.F.M.; FERREIRA, A.S.; SANTOS, F.A. Exigência de lisina digestível para suínos machos castrados de alto potencial genético para deposição de carne magra na carcaça dos 30 aos $60 \mathrm{~kg}$. Revista Brasileira de Saúde e Produção Animal [Online], v.10, n.1, p.106114, 2009.

PUPA, J.M.R.; ORLANDO, U.A.D.; DONZELE, J.L. Requerimentos nutricionais de suínos nas condições brasileiras. In: WORKSHOP LATINO AMERICANO BIOLATINA, NUTRIÇÃO DE AVES E SUÍNOS, 1., 2001, Foz do Iguaçu. Anais... Foz do Iguaçu: 2001. p.143-153.

REN, J.B.; ZHAO, G.Y.; LI, Y.X.; MENG, Q.X. Influence of dietary lysine level on whole-body protein turnover, plasma IGF-I, GH, and insulin concentration in growing pigs. Livestock Science, v.110, p.126-132, 2007.

ROSSONI, M.C.; DONZELE, J.L.; SILVA, F.C.O.; OLIVEIRA, R.F.M.; ABREL, M.L.T.; SANTOS, F.A.; KILL, J.L.; PEREIRA, C.M.C. Exigência de lisina digestível de fêmeas suínas selecionadas para deposição de carne magra, na carcaça dos 15 aos 30kg. Revista Brasileira de Saúde e Produção Animal [Online], v.10, n.3, p.586-595, 2009. 
Rev. Bras. Saúde Prod. Anim., Salvador, v.13, n.2, p.433-443 abr./jun., 2012 http://www.rbspa.ufba.br ISSN 15199940

ROSTAGNO, H.S.; ALBINO, L.F.T.; DONZELE, J.L. GOMES, P.C.;

OLIVEIRA, R.F.; LOPES, D.C.; FERREIRA, A.S.; BARRETO, S.L.T.

Composição de alimentos e exigências nutricionais de aves e suínos: tabelas brasileiras. Viçosa, MG: Universidade Federal de Viçosa, 2000. 141p.

ROSTAGNO, H.S.; ALBINO, L.F.T.; DONZELE, J.L.; GOMES, P.C.; OLIVEIRA, R.F.; LOPES, D.C.; FERREIRA, A.S.; BARRETO, S.L.T. Composição de alimentos e exigências nutricionais de aves e suínos: tabelas brasileiras. 2.ed. Viçosa, MG:

Universidade Federal de Viçosa, 2005. $186 \mathrm{p}$.

SANTOS, F.A; DONZELE, J.L.; SILVA, F.C.O.; OLIVIERA, R.F.M.; ABREU, M.L.T.; SARAIVA, A.; HAESE, D.; LIMA, A.L. Níveis de lisina digestível para suínos machos castrados de alto potencial genético dos 95 aos $125 \mathrm{~kg}$. Revista Brasileira de Zootecnia, v.40, n.5, p.1038-1044, 2011.

SILVA, D.J. Análise de alimentos: métodos químicos e biológicos. 3.ed. Viçosa, MG: Universidade Federal de Viçosa, 2002. 59p.
SILVA, F.C.O.; DONZELE, J.L.; OLIVIERA, R.F.M.; MARCATTI NETO, A.; PAULA, E. Influência do número de animais e tipo de comedouro na unidade experimental sobre as exigências nutricionais e composição de carcaça de suínos em terminação.

Revista Brasileira de Zootecnia, v.38, n.6, p.1059-1067, 2009.

SOUZA, A.M. Exigências nutricionais de lisina para suínos mestiços, de $\mathbf{1 5}$ a 95kg de peso. 1997. 81p. Dissertação (Mestrado em Zootecnia) Universidade Federal de Viçosa, Viçosa.

UNIVERSIDADE FEDERAL DE VIÇOSA - UFV. SAEG - Sistemas de Análises Estatísticas e Genéticas. Versão 8.0. Viçosa, MG: Central de Processamento de Dados, 2005.

WARNANTS, N.; VAN OECKEL, M.J.; PAEPE, M. Response of growing pigs to different levels of ileal standardized digestible lysine using diets balanced in threonine, methionine and tryptophan. Livestock Production Science, v.82, n.2/3, p.201-209, 2003.

Data de recebimento: 23/05/2011

Data de aprovação: 10/02/2012 